\title{
IMPLEMENTATION OF CRYPTOGRAPHY AND STEGANOGRAPHY FOR TEXT ON COVER IMAGE USING AES AND F5 ALGORITHM
}

\author{
Ratna Astuti Nugrahaeni ${ }^{1}$, R. Rumani M. ${ }^{2}$, Surya Michrandi Nasution ${ }^{3}$ \\ ${ }^{1,2,3}$ School of Electrical Engineering, Telkom University \\ 1ㅁatnaan@gmail.com, ${ }^{2}$ rumani@telkomuniversity.ac.id, ${ }^{3}$ michrandi@telkomuniversity.ac.id
}

\begin{abstract}
This journal explains about implementation that combine both cryptography and steganography method for texton cover image to increase the security level. Text will be encrypted with AES algorithm, and then it will be embedded to the cover image using $F 5$ algorithm. The implemented AES algorithm has a good performance, with Avalanche Effect value ranges from 0.43 - 0.59. The resulting image, or stego image, has a very similar histogram with the original image, so there is no significant difference between the two of them. However, the file size change about $1.25-3.25$ times larger than theoriginal image. If noise or disruption is given to stego image, the information can not be extracted.
\end{abstract}

Keywords: cryptography, steganography, AES, F5

\section{Introduction}

Communication has been used since a long time ago, either to exchange information or just simply communicating. Everyone who communicate might have different needs, and sometimes they want to communicate credential information. A cryptography method can be used to encrypt the information using a specific key so that it will not be easily interrupted by third party. However, this method is very flashy, thus may arouse suspiciousness from everyone who sees it.

To solve this problem, there is a steganography method which use a cover media to hide the information. The media can be image, audio, or even a video file. This method is made so that when other people see it, they will not realize that there is an information hidden inside.

The writer made an implementation to make the steganography method more secure, by using encryption process before embedding information to the cover image. The cryptography algorithm is AES128 , and the steganography algorithm is F5.

\section{AES Cryptography Algorithm}

AES or Advanced Encryption Standard is asymmetric algorithm. This standard can be used with three key lengths: 128 bits, 192 bits, and 256 bits. The block size of this algorithm is 128 bits, that can be seen on Figure 1. AES is the first standard to be approved by NSA (National Security Agency) for secret information changing [6].

The key length will determine the number of transformation cycle from plain text into cipher text, as seen below:

a. 10 cycle for 128 bit key length;

b. 12 cycle for 192 bit key length;

c. 14 cycle for 256 bit key length;
Generally, the algorithm consists of these steps:

a. Initial Round, doing Add Round Key, which is doing an XOR process between the plaintext and cipher key.

b. Cycle of sub-processes: Sub Bytes, substituting the data with S-Box; Shift Rows, shifting the data by rows; Mix Columns, scrambling the data on each array state; and Add Round Key, XOR the data with cipher key.

c. Final Round, which consists of: Sub Bytes, Shift Rows, and Add Round Key.

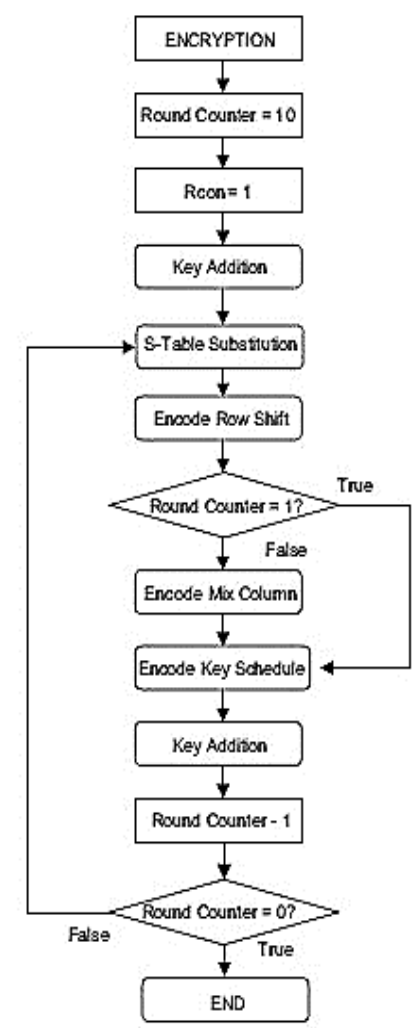

Figure 1. Encryption Process of AES-128 [8] 


\section{Steganography}

Steganography is a technique to hide the informationon a cover media, which can be image, audio, or video file [4].This methods is used so that beside the sender and the recipient, no one will know the existence of the information.

There are some criteria on steganography:

a. Imperceptibility, the existence of information can not be seen visually.

b. Fidelity, the quality of cover media does not change significantly.

c. Recovery, the embedded information can be extracted Steganography method uses a cover media and the information to be hide, or hidden text [7].

The process of steganography can be seen on the block diagram on Figure 2.

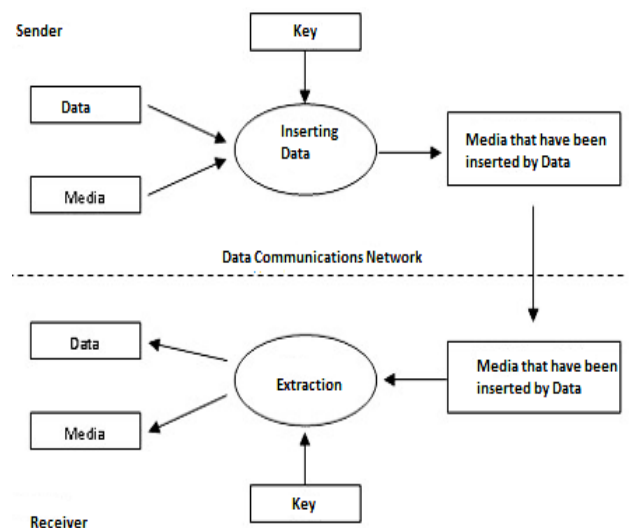

Figure 2. Block Diagram of Steganography Process [2]

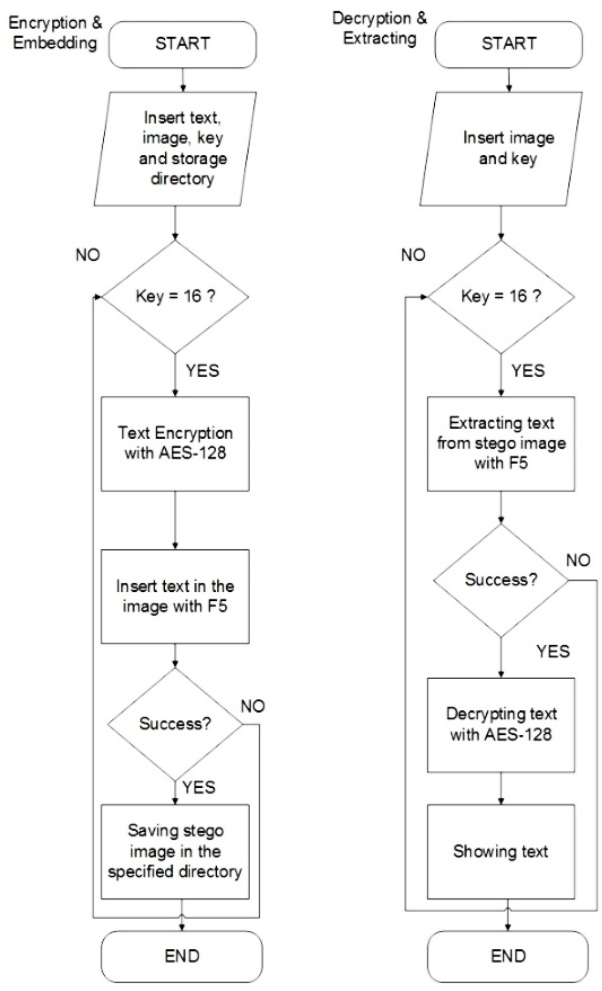

Figure 3. Flowchart of the System

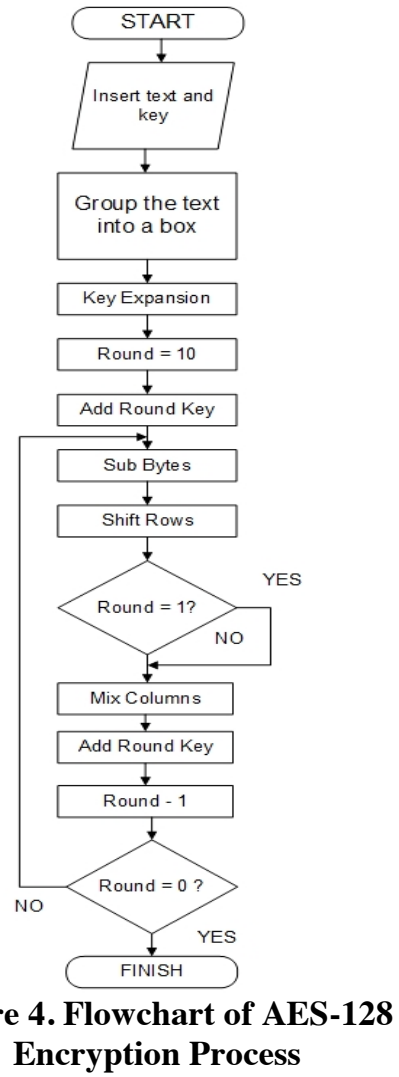

\section{F5 Steganography Algorithm}

The use of image as the cover media on steganography process has a limited capacity. To prevent a detection or attack, the information has to be embedded evenly on the cover.

F5 algorithm uses permutative straddling, which randomize the coefficient by permutation, and then embed the information. Permutation depends on the key derivated from the password. The coefficients will then be processed by Huffman Coder, so that the authorized recipient will be able to redo the permutation and get the information. F5 algorithm also uses matrix encoding, so that the embedding process can be more efficient.

\section{System Design}

If the implementation is finished, the system will have these specifications:

a. Can do cryptography process, either encryption or decryption on the text inputted by the user;

b. Can do steganography process, either to embed or to extract the information from the inputted stego image.

Implementation is done by making an application where the user can specified the cover image, text to be hidden, and the key. The output is a stego image which has a good performance; which can be seen by calculating the MSE (Mean Square Error) and PSNR (Peak Signal to Noise Ratio) value.

The parameter used to see the stego image performance is it's resistance of Salt and Pepper 
noise, and disruption like cropping and compression process. The MSE shows the average square error, and PSNR shows the comparison between the maximum signal value and the noise affecting the signal. The MSE and PSNR equations are as shown below:

$$
\begin{gathered}
M S E=\frac{1}{m n} \sum_{i}^{m} \sum_{j}^{n}\|I(i, j)-K(i, j)\|^{2} \\
P S N R=10 \cdot \log \left(\frac{M A X_{I}^{2}}{M S E}\right)=20 \cdot \log \left(\frac{M A X_{I}}{\sqrt{M S E}}\right)
\end{gathered}
$$

The design includes flowchart of the system, system modelling, and the interface design. The system in general can be seen in Figure 3. The encryption process of AES-128 algorithm can be seen in Figure 4 and Figure 5, meanwhile the decryption process of AES-128 can be seen in Figure 6 and the extraction process of F5 algorithm can be seen in Figure 7.

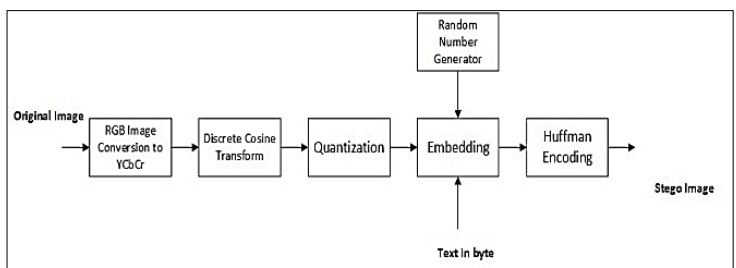

Figure 5. Diagram of F5 Embedding Process

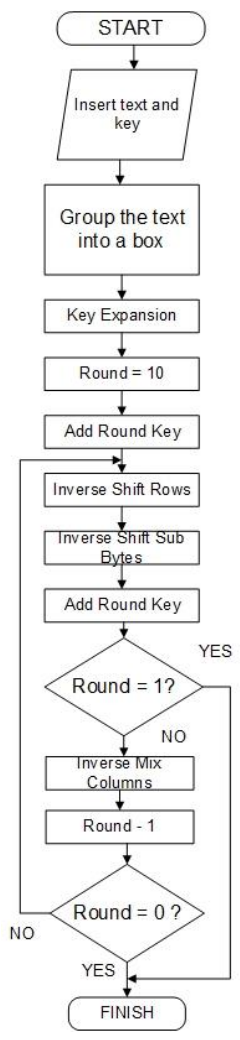

Figure 6. Flowchart of AES-128 Decryption Process

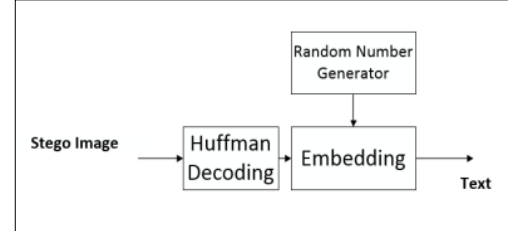

Figure 7. Block Diagram of F5 Extraction Process

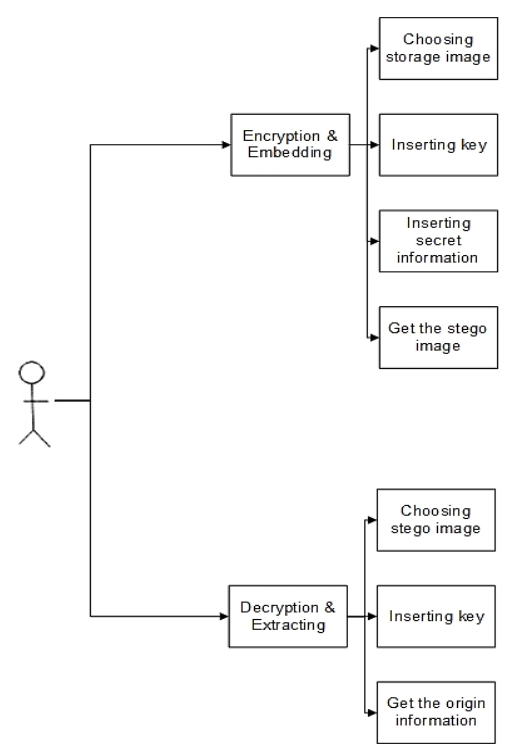

Figure 8. Activity Diagram

USER

SYSTEM

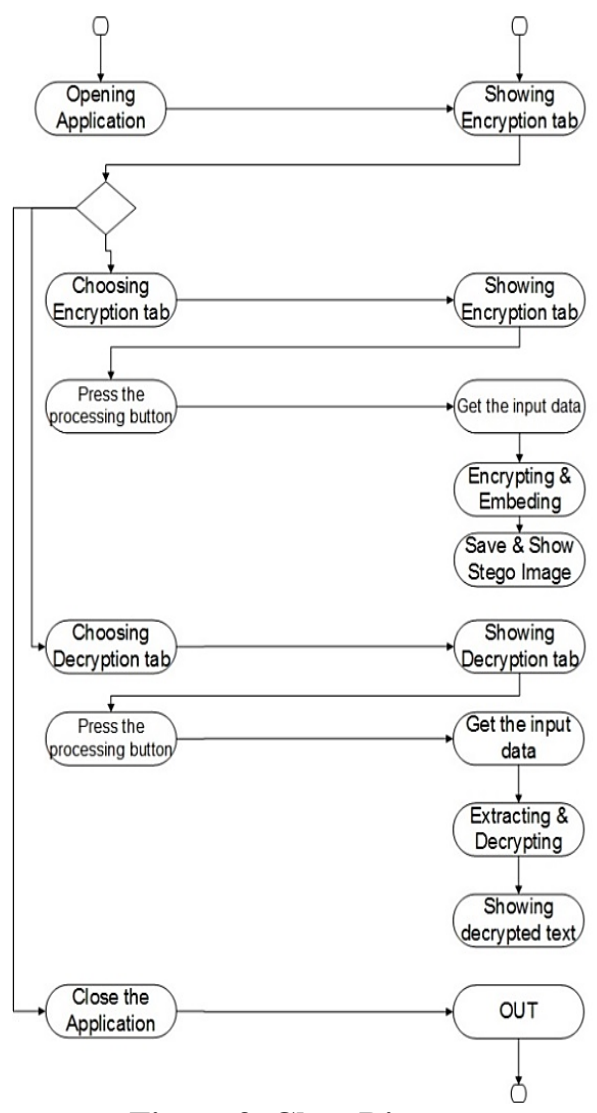

Figure 9. Class Diagram 


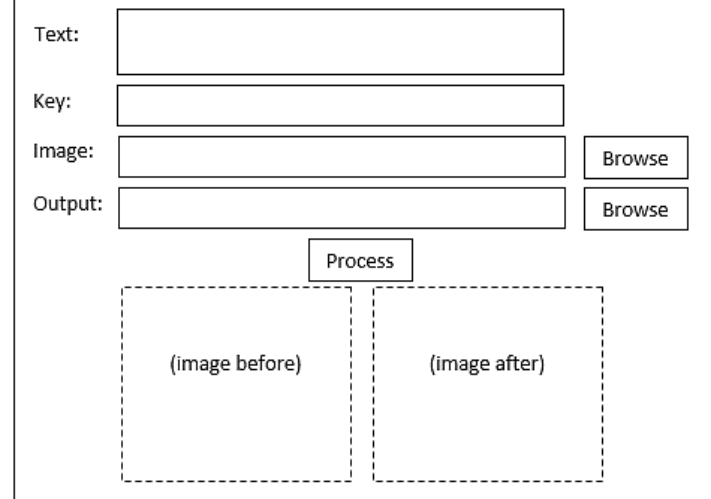

Figure 10. Interface Design

of Encryption and Embedding

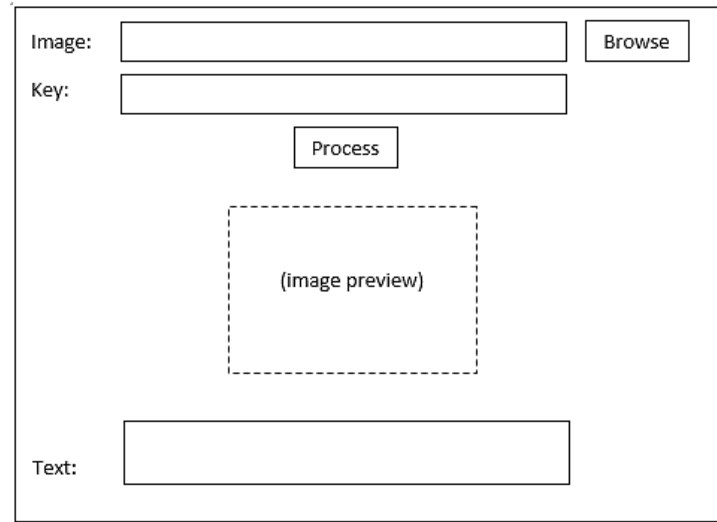

Figure 11. Interface Design of Extraction and Decrypting

Table 1. Encryption and Embedding Testing

\begin{tabular}{|c|c|}
\hline \multicolumn{2}{|r|}{ Case and Result (Normal Data) } \\
\hline Data Input & $\begin{array}{l}\text { Text: "program studi sistem komputer angkatan 2009"; } \\
\text { Key: "programstudicesk" (16 karakter); } \\
\text { Image: orchid.jpg; } \\
\text { Output: (saving directory) }\end{array}$ \\
\hline $\begin{array}{l}\text { Expected } \\
\text { Result }\end{array}$ & $\begin{array}{l}\text { After inputting the text, key, image, and output directory, } \\
\text { theuser can start the process by clicking the Process } \\
\text { button. Theprocess will start by encrypting the text and } \\
\text { embedding it intothe cover image. If the text is not more } \\
\text { than } 500 \text { characters, andthe key is exactly } 16 \text { characters, } \\
\text { the stego image will be savedto the output directory. }\end{array}$ \\
\hline Observation & $\begin{array}{l}\text { Stego image is saved into the output directory with a } \\
\text { goodquality. }\end{array}$ \\
\hline Conclusion & Accepted. \\
\hline \multicolumn{2}{|c|}{ Case and Result (Wrong Data) } \\
\hline Data Input & $\begin{array}{l}\text { Text: (none); } \\
\text { Key: "programstudicesk"; } \\
\text { Image: orchid.jpg; } \\
\text { Output: (output directory) }\end{array}$ \\
\hline $\begin{array}{c}\text { Expected } \\
\text { Result }\end{array}$ & Showing error message. \\
\hline Observation & $\begin{array}{l}\text { The process can not be done because the text to be } \\
\text { embeddedhas not been specified. An error message "Text } \\
\text { is empty!"occurred. }\end{array}$ \\
\hline Conclusion & Accepted. \\
\hline
\end{tabular}

\section{System Modelling}

The application is made in one package, using 10 classes as seen in Figure 9. Based on the input and output requirements, the interface design can be seen in Figure 10 and Figure 11 (with the information on Table 1 and 2).
Table 2. Extracting and Decryption Testing

\begin{tabular}{|c|c|}
\hline \multicolumn{2}{|r|}{ Case and Result (Normal Data) } \\
\hline Data Input & $\begin{array}{l}\text { Image: orchidstego.jpg; } \\
\text { Key: "programstudicesk" ( } 16 \text { characters) }\end{array}$ \\
\hline $\begin{array}{l}\text { Expected } \\
\text { Result }\end{array}$ & $\begin{array}{l}\text { After inputting the stego image and key, user can start } \\
\text { theprocess by clicking the Process button. The process will } \\
\text { start byextracting information from the stego image, and then } \\
\text { it will bedecrypted using the key. If the key is exactly } 16 \\
\text { characters, theextracted text will be shown. }\end{array}$ \\
\hline Observation & Text is successfully extracted, and is shown in the text box. \\
\hline Conclusion & Accepted. \\
\hline \multicolumn{2}{|r|}{ Case and Result (Wrong Data) } \\
\hline Data Input & $\begin{array}{l}\text { Image: orchidstego.jpg; } \\
\text { Key: "programstudiskce" (16 characters, different than } \\
\text { theencryption key) }\end{array}$ \\
\hline $\begin{array}{l}\text { Expected } \\
\text { Result }\end{array}$ & $\begin{array}{l}\text { After inputting the stego image and key, user can start } \\
\text { theprocess by clicking the Process button. The process will } \\
\text { start byextracting information from the stego image, and then } \\
\text { it will bedecrypted using the key. If the key is right, the } \\
\text { extracted text willbethe same like the original one. }\end{array}$ \\
\hline Observation & $\begin{array}{l}\text { Text is successfully extracted and is shown in the text box, } \\
\text { butdifferent than the original text. }\end{array}$ \\
\hline Conclusion & Accepted. \\
\hline \multicolumn{2}{|r|}{ Case and Result (Wrong Data) } \\
\hline Data Input & $\begin{array}{l}\text { Image: orchid.jpg; (bukan citra stego) } \\
\text { Key: "programstudicesk" }\end{array}$ \\
\hline $\begin{array}{l}\text { Expected } \\
\text { Result }\end{array}$ & Showing error message. \\
\hline Observation & $\begin{array}{l}\text { An error message saying that there is no message extracted } \\
\text { isshown. }\end{array}$ \\
\hline Conclusion & Accepted. \\
\hline
\end{tabular}

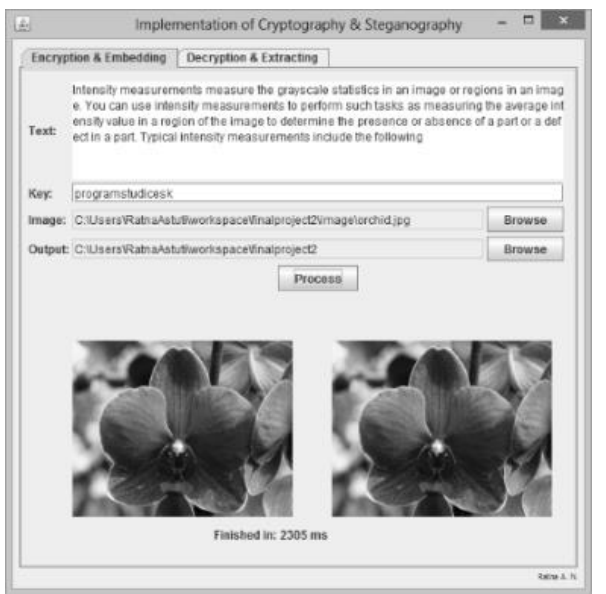

Figure 12. Interface of Encryption and Embedding

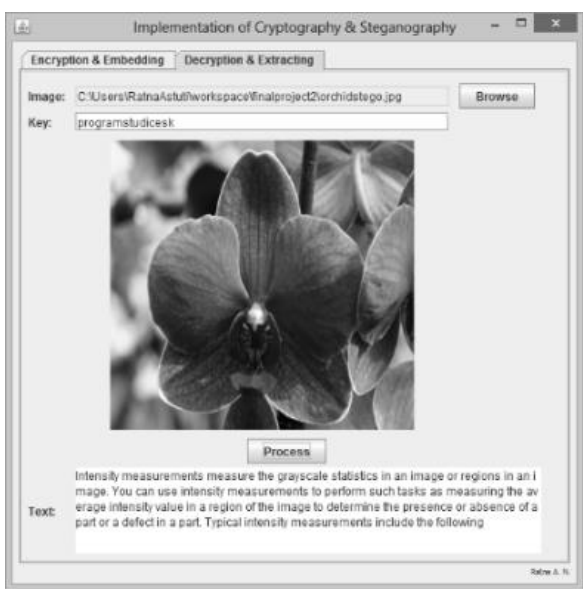

Figure 13. Interface of Decryption and Extracting

\subsection{System Implementation}

Based on the system design, the implementation needs a hardware and software which can run Java 
desktop application. The implementation is made using Eclipse Juno on a Windows 8 operating system, with $2.2 \mathrm{GHz}$ processor. The use lower specification of hardware and software can be done, with the minimum requirements as follow:

\subsubsection{Minimum Hardware Requirements}

The hardware that can be used should met the minimum requirement as follow: $1.5 \mathrm{GHz}$ processor; 1 GB RAM; and 300 MB hard disk.

\subsubsection{Minimum Software Requirements}

The software that can be used should met the minimum requirement as follow:

a. Windows XP operating system;

b. JDK 1.6.0 (Java Development Kit);

c. JRE 1.6.0 (Java Runtime Environment).

\subsection{Interface}

The system is made as a desktop application with the interface as shown in Figure 12 and 13.

\section{Testing}

To see the performance of the implemented system, some testing have been done to see the functionality of the system, the resistance of stego image, and the cryptography algorithm performance.

\subsection{Black-box Testing}

This testing focused on the system functionality, to see whether both the input and output are the same as the expected result. Based on the equation (1) and (2), the MSE and PSNR values are shown on Table 5.

Table 3. Comparison of Original and Stego Image

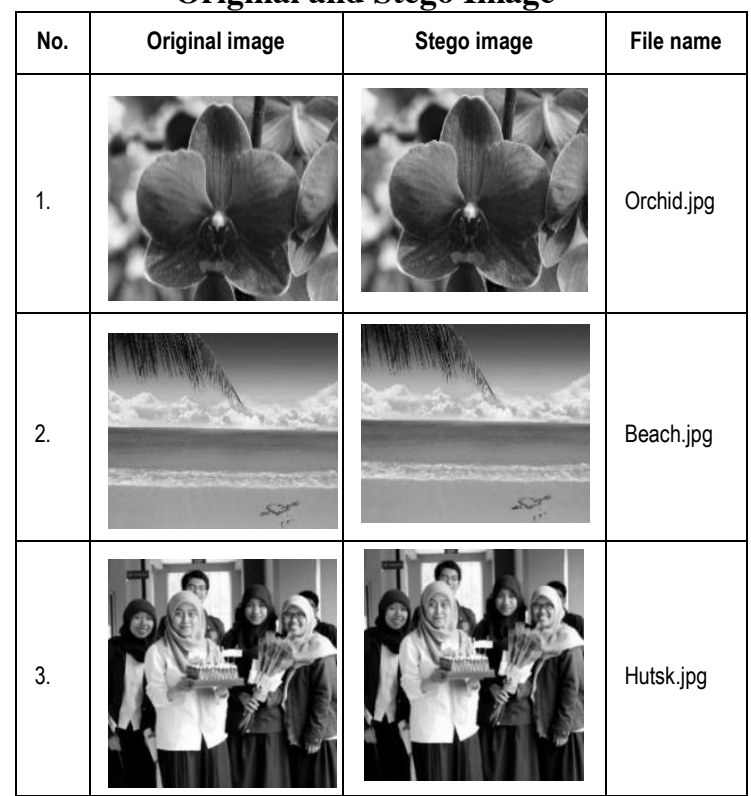

Table 4. Image's Resolution and Size

\begin{tabular}{|c|c|c|c|c|c|}
\hline \multirow{2}{*}{ No } & File & \multicolumn{2}{|c|}{ File resolution } & \multicolumn{2}{c|}{ File size } \\
\cline { 3 - 6 } & name & Ori img & Stego img & Ori img & Stego img \\
\hline 1. & Orchid.jpg & $1920 \times 1825$ & $1920 \times 1825$ & $383 \mathrm{~KB}$ & $917 \mathrm{~KB}$ \\
\hline 2. & Beach.jpg & $1600 \times 1200$ & $1600 \times 1200$ & $399 \mathrm{~KB}$ & $882 \mathrm{~KB}$ \\
\hline 3. & Hutsk.jpg & $720 \times 720$ & $720 \times 720$ & $64.8 \mathrm{~KB}$ & $211 \mathrm{~KB}$ \\
\hline
\end{tabular}

Table 5. MSE and PSNR Value

\begin{tabular}{|c|c|c|c|}
\hline No & File name & MSE & PSNR \\
\hline 1. & Orchid.jpg & 0.8504 & $48.86 \mathrm{~dB}$ \\
\hline 2. & Beach.jpg & 3.9491 & $42.19 \mathrm{~dB}$ \\
\hline 3. & Hutsk.jpg & 1.2822 & $48.08 \mathrm{~dB}$ \\
\hline
\end{tabular}

Table 6. Salt and Pepper Test

\begin{tabular}{|c|c|c|}
\hline Stego image & Stego image+noise & $\begin{array}{c}\text { Extracted } \\
\text { text }\end{array}$ \\
\hline & & (nothing) \\
\hline & & (nothing) \\
\hline & & \\
\hline
\end{tabular}

Table 7. Cropping Test

\begin{tabular}{|l|l|l|}
\hline Stego image & Stego image+noise & $\begin{array}{c}\text { Extracted } \\
\text { text }\end{array}$ \\
\hline (nothing) & (nothing) \\
\hline & & \\
\hline
\end{tabular}

Table 8. Compression Test

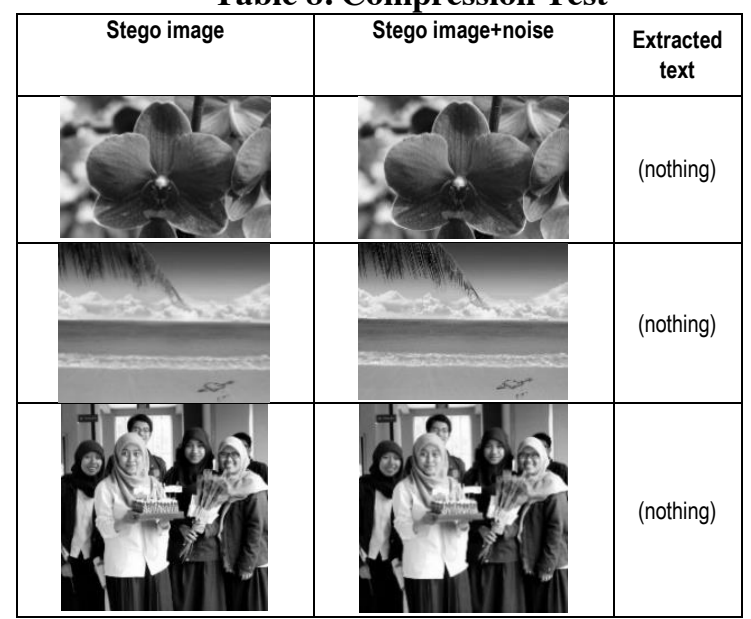


The result of PSNR ranges from $42 \mathrm{~dB}-49 \mathrm{~dB}$. Standard PSNR value for image with bit depth of 8 bits is $30 \mathrm{~dB}-40 \mathrm{~dB}$ or more, as seen on Table 5 . Thus, the resulting image has a good performance.

\subsubsection{Image's Resistance Testing}

\subsubsection{Salt and Pepper Noise}

This testing is done by adding noise to stego image,which is a black and/or white pixel randomly on the entire image, as seen on Table 6 .

\subsubsection{Cropping Process}

This testing is done after cropping the image by $50 \%$, as seen on Table 7 .

\subsubsection{Compression Process}

This testing is done after doing a compression to the stego image with the quality of 70 , as seen on Table 8.

From the Salt and Pepper testing, we can see that if there's noise on the stego image, the coefficient's value will change and text can not be extracted. In the cropping test, some of the pixel is cropped and some embedded information might have lost with it. The amount of coefficients also reduced due to the cropping and it will cause an extraction failure. From the compression testing, the text can not be extracted because the compression process will change the coefficient's value.

\subsubsection{White-box Testing}

This testing is done using test case.

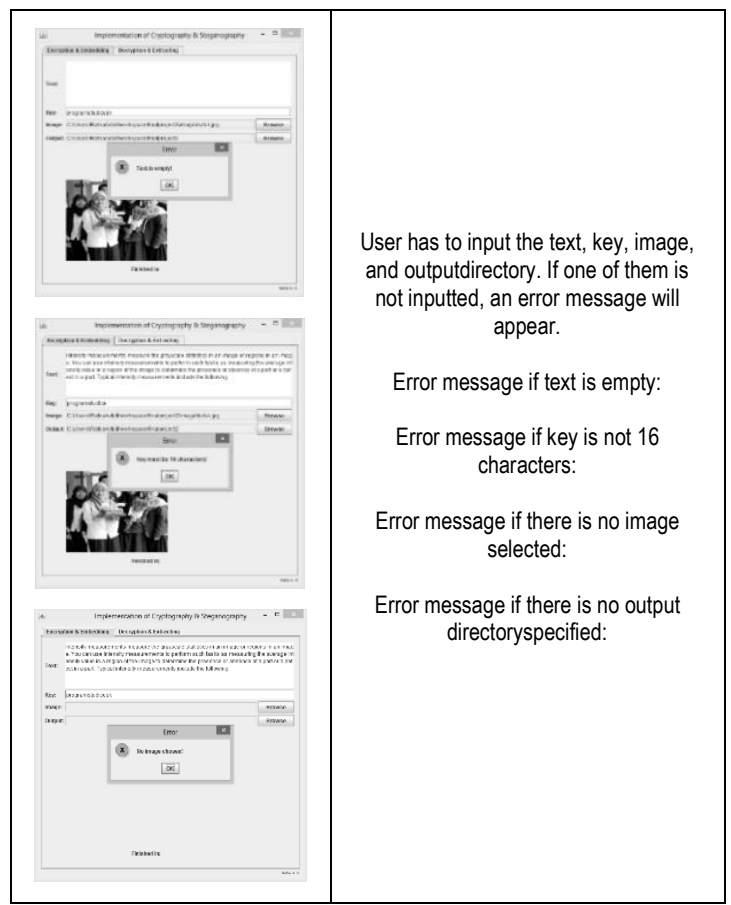

(a)

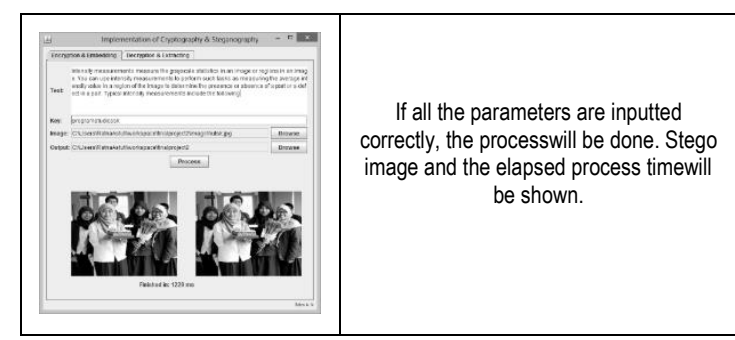

(b)

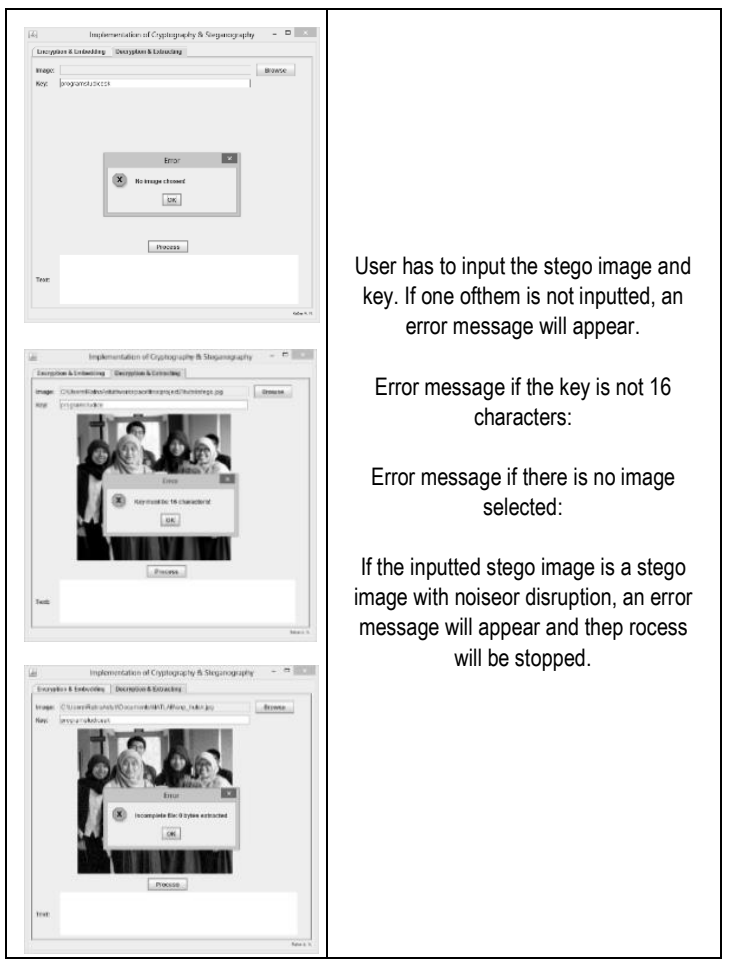

(c)

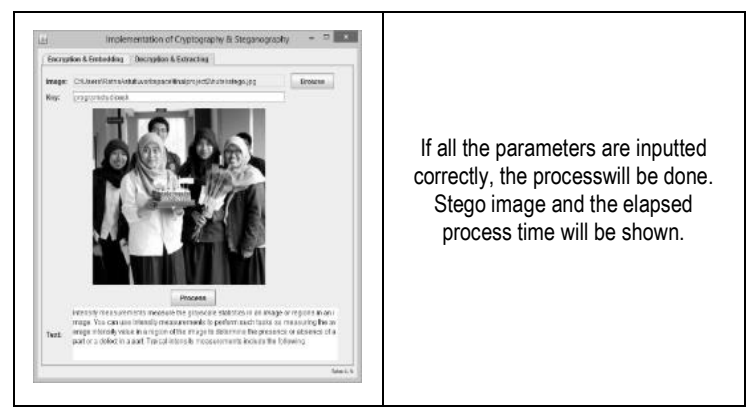

(d)

Figure 14. White-box Testing. (a) Encryption and Embedding (Error message), (b) Encryption and Embedding, (c)Extracting and Decryption (Error message), and (d) Extracting and Decryption

\subsection{Avalanche Effect Testing}

In cryptography, the result is very unique, differentthan the inputted data. A little change on the input data,the result will change drastically. This is called Avalanche Effect.

From the test, just one bit changes in the input will change the output from $56-76$ bits. This shows 
that the implemented AES-128 algorithm has a good performance, as seen on Table 9. It changes half of the cipher text which is the best proportion, rather than changing too little or too much.

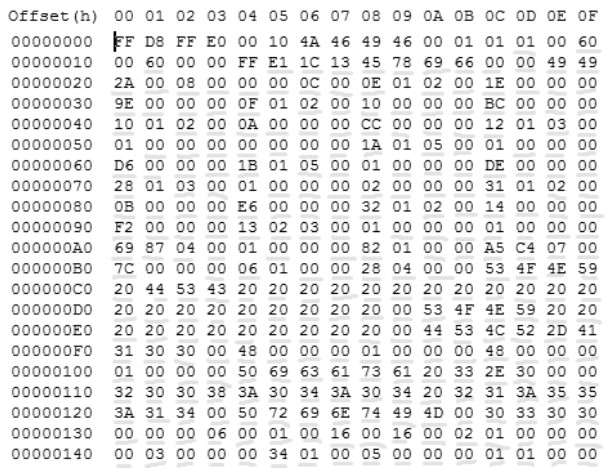

(a)

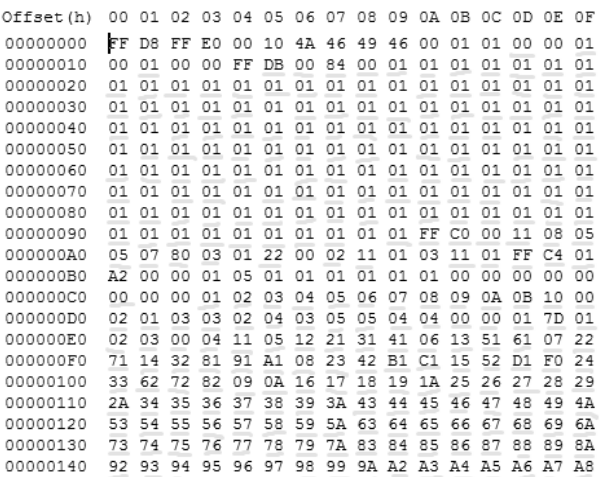

(b)

Figure 15. Comparison of Hexa Decimal from (a) orchid.jpg and (b) orchidstego.jpg

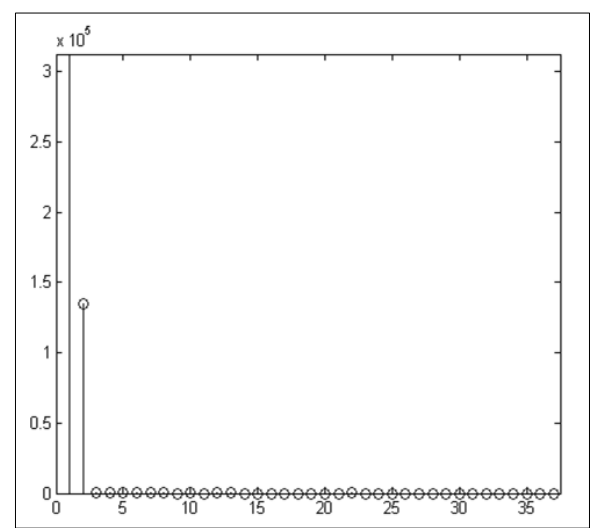

Figure 16. Histogram's Difference from orchid.jpg and orchidstego.jpg

Table 9. Avalanche Effect Testing

\begin{tabular}{|c|c|c|}
\hline Plain text & Cipher text & $\begin{array}{c}\text { Avalanche } \\
\text { Effect }\end{array}$ \\
\hline $\begin{array}{l}33333333333333 \quad 33 \\
3333333333333333\end{array}$ & $\begin{array}{l}\text { D3 F5 51 F6 } 883865 \text { C5 } \\
\text { 8E } 72 \text { CE } 20 \text { F7 6D C4 8C }\end{array}$ & \multirow{2}{*}{$\begin{array}{c}0.59375 \\
\text { (76 bit } \\
\text { change) }\end{array}$} \\
\hline $\begin{array}{l}3233333333333333 \\
3333333333333333\end{array}$ & $\begin{array}{l}8 B \text { C7 45 D9 75 C6 DA 1A } \\
\text { A8 } 2800152056319 A\end{array}$ & \\
\hline $\begin{array}{l}41 \text { 4E 47 4B 41 54 414E } \\
2032303039677565\end{array}$ & $\begin{array}{l}\text { F0 E1 F1 A4 2F 9D } 2728 \\
\text { A3 } 9209 \text { F3 } 22976 \text { A } 72\end{array}$ & \multirow{2}{*}{$\begin{array}{c}0.4375 \\
(56 \mathrm{bit} \\
\text { change) }\end{array}$} \\
\hline $\begin{array}{l}41 \text { 4E 47 4B 41 54 414D } \\
2032303039677565\end{array}$ & $\begin{array}{l}46 \text { FF E3 C1 FF 9C } 82 \mathrm{AB} \\
\text { E9 E7 9D } 7390 \text { B0 } 9669\end{array}$ & \\
\hline
\end{tabular}

\section{Conclusion}

From the implementation and testing result, the conclusions are as follow:

a. Changes in file size depends on the color intensity. Image with the smalles size changes is orchid2.jpg with $500-2000$ pixel for each color intensity value. Image with the biggest size change is hutsk.jpg with $1000-7000$ pixel for each color intensity value.

b. Stego image size is $1.25-3.25$ times larger than the original image, which can be the result of Huffman Encoding, because when image is being written, the Huffman Table is included, which size is based on the encoding result.

c. Stego image is very sensitive to noise or disruption. A slight crop $(0.002 \%)$ from the stego image can cause extraction failure.

d. The cryptography algorithm has a good performance, with the resulting changes from 56 -76 bit for 1 bit changes from the input.

\section{References}

[1] Ariyus, Dony, "Pengantar Ilmu Kriptografi: Teori, Analisis, dan Implementasi", Yogyakarta, Penerbit Andi, 2008.

[2] Batarius, P., and M. Maslim, "Perbandingan Metode Dalam Teknik Steganografi”, Semantik 2012.

[3] Cheddad, Abbas, "Digital Image Steganography", VDM Publishing, 2009.

[4] Cox, Ingemar J., "Digital Watermarking and Steganography", Burlington, Morgan Kaufmann Publisher, 2008.

[5] Fridrich, Jessica, "Steganography in Digital Media: Principles, Algorithms, and Applications", Cambridge University Press, 2009.

[6] Hulme, F. Edward, "Cryptography: Or, the History, Principles, and Practice of CipherWriting", Biblio Bazaar, 2010.

[7] Singh, Ram Kumar and Amit Asthana, "Steganography", Lambert Academic Publishing, 2012.

[8] Surian, D., "Algoritma Kriptografi AES Rijndael", TESLA Jurnal Teknik Elektro UNTAR, 8(2), pp-97, 2009. 